\title{
Long term survival and nutritional data in patients with cystic fibrosis treated in a Danish
} centre

\author{
Martha Nir, Susanne Lanng, Helle Krogh Johansen, Christian Koch
}

\begin{abstract}
Background - Adequate nutrition and optimal treatment of bronchopulmonary infections are both of critical importance in maintaining the health of patients with cystic fibrosis. The cystic fibrosis centre in Copenhagen has followed a regimen of very early and aggressive antimicrobial treatment, especially against Pseudomonas aeruginosa infection. An unrestricted diet of low fat and high protein without hyperalimentation was recommended before 1985 which was then changed to a high fat, high calorie intake. Methods - The overall impact of the treatment regimen was evaluated by a cross sectional analysis of all 223 patients who attended the centre in 1989. Growth and nutritional parameters were combined with lung function parameters and with a retrospective analysis of chronic $P$ aeruginosa infection and its duration. Survival curves for all 313 patients treated at the centre since 1949 were calculated.
\end{abstract}

Results - All the patients with cystic fibrosis had normal height, although the final height was achieved a little later than in healthy controls. Body weight was lower than normal in males above 15 and in females above 10 years of age. The body mass index (BMI), which was approximately $98 \%$ of normal in the younger patients, declined to $90 \%$ in adult men and to $83 \%$ in adult women with cystic fibrosis, and was strongly correlated with lung function parameters. In 1989 the median age of survival of all patients treated in the centre since 1949 was 30 years ( 32 years in males and 29 years in females).

Conclusions - The overall treatment regimen in the cystic fibrosis centre in Copenhagen is associated with growth and survival rates that are at least equal to those in other cystic fibrosis centres in other countries.

(Thorax 1996;51:1023-1027)

Keywords: cystic fibrosis, survival, nutrition.

Nutritional recommendations for patients with cystic fibrosis differ among centres, with most recommending a high fat, high calorie diet. ${ }^{1}$ This is supplemented in some centres by hyperalimentation through nasogastric ${ }^{1-3}$ gastrostomy/jejunostomy tubes, ${ }^{1-9}$ and .occasionally with parenteral nutrition. ${ }^{1}$ However, there is disagreement as to the effect of these procedures on lung function and on the prognosis. ${ }^{1-11}$

Corey et al in a comparative study between patients with cystic fibrosis in Toronto and Boston $^{12}$ concluded that the longer survival of the patients in Toronto was due mainly to better nutritional status as a result of hyperalimentation, as lung function was similar in the two groups.

At the cystic fibrosis centre in Copenhagen a low fat, high protein diet was recommended until 1985, after which the diet became unrestricted and a high fat, high calorie diet is now recommended comprising $100-150 \%$ of the total calorie intake recommended by the World Health Organisation for healthy persons. The calorie intake is distributed as $40 \%$ fat, $20 \%$ protein, and $40 \%$ carbohydrates. Individual food intake is supplemented by an amount of pancreatic enzymes that allows normal height and weight gain and no steatorrhoea. Moreover, the treatment regimen includes rigorous control of infection and aggressive antimicrobial treatment. ${ }^{1314}$ Briefly, specimens of lower respiratory tract secretions are obtained by expectoration or nasolaryngeal suction at least once every month on a regular basis in all patients as well as at clinic visits in between the monthly visits because of acute signs or symptoms of infection. Peroral antimicrobial chemotherapy is instituted for 14 days whenever pathogenic bacteria are identified by microscopy and culture according to fixed protocols, even in the absence of signs or symptoms of lower respiratory tract infection. ${ }^{13}$ In addition, since 1975-6 elective 14 day courses of intravenous antipseudomonas chemotherapy have been administered approximately every third month to all patients with chronic $P$ aeruginosa infection, usually a combination of tobramycin and a suitable beta-lactam antibiotic. ${ }^{1314}$ In unstable patients the intervals between courses may be shortened and/or oral quinolones may be given and, since 1987, all patients chronically infected with $P$ aeruginosa have taken regular inhalations of colistin twice daily.

In this retrospective study we have tried to evaluate the impact of major changes in nutrition and in antimicrobial treatment over several decades in the hope of adding some information on these issues.

\section{Methods}

The study period for the cross sectional investigation of growth parameters was the whole 
of 1989 and the population studied comprised all 223 patients ( 115 males) with cystic fibrosis attending the centre during this period. All were treated entirely at the centre and many from the time of diagnosis. The mean age of the patients was 14.9 years (range 4 months to 41 years) with no difference between males and females. The patients were seen monthly in the outpatient clinic, and each visit included measurement of lung function by spirometric tests, height and weight, and bacteriological investigation of lower respiratory tract secretions. ${ }^{1314}$ The number of capsules of enterosoluble microspheres (Pancrease, Cilag, Denmark) taken per meal was recorded. Values were standardised as per $\mathrm{m}^{2}$ of body surface and per $\mathrm{kg}$ body weight.

\section{GROWTH PARAMETERS}

The growth parameters used were the height and weight standard deviation scores (HSDS, WSDS), also called $\mathrm{Z}$ scores, and the body mass index (BMI).

The HSDS and WSDS were determined as actual height or weight minus the median normal height or weight for age and sex divided by SD for age and sex. The actual height and weight were median values of at least six measurements during the year of the study. The median values of height and weight and SD in healthy Danish children up to 18 years of age were derived from tables, ${ }^{15}$ whereas the corresponding values for adults were from a recent study of a large unselected group of normal inhabitants in the Copenhagen area conducted between 1981 and 1983. ${ }^{16}$

The BMI in patients below 19 years was calculated as actual log weight $(\mathrm{kg})-0.0008$ $\times$ height $(\mathrm{cm})^{17}$ and expressed as a percentage of the BMI calculated from the tables for median height and weight in Danish children. ${ }^{15}$ In patients older than 18 years the BMI was calculated as actual weight/height ${ }^{2}$ and expressed as a percentage of the median BMI in healthy Danish men and women. ${ }^{16}$

\section{PULMONARY FUNCTION}

The median values of at least six recordings during the study period of forced expiratory volume in one second $\left(\mathrm{FEV}_{1}\right)$ and forced vital capacity (FVC) expressed as a percentage of predicted values for height and $\operatorname{sex}^{18}$ were used.

\section{SURVIVAL ANALYSIS}

To determine the median survival of the patients life table analysis was performed on all patients with cystic fibrosis born without meconium ileus who attended the cystic fibrosis centre from 1949 to December 1989. Three hundred and thirteen patients (163 men) were included in the survival analysis, 221 of whom were still alive on 31 December 1989. Twenty six patients with meconium ileus at birth and two who died from complications following premature birth were not included in the survival analysis to allow a comparison to be made with published analyses of survival from other centres which have also excluded patients born with meconium ileus.

\section{INFECTIONS}

The onset of chronic $P$ aeruginosa infection was defined as a positive culture in the lower respiratory tract secretions at each of six consecutive visits or for a shorter time but with a significant increase in specific anti- $P$ aeruginosa serum antibodies.

The genotyping was performed as described previously. ${ }^{19}$

\section{DATA ANALYSIS}

The 5\% level of significance was chosen (twotailed). To estimate correlations between the variables the Spearman rank correlation test was used. Data were compared using the Fisher exact test and unpaired $t$ tests. For comparison of two groups the Mann-Whitney test was used. Survival rates were calculated by the life table method (log rank analysis).

\section{Results}

The overall median height of both male and female patients was $0.46 \mathrm{SD}$ below normal
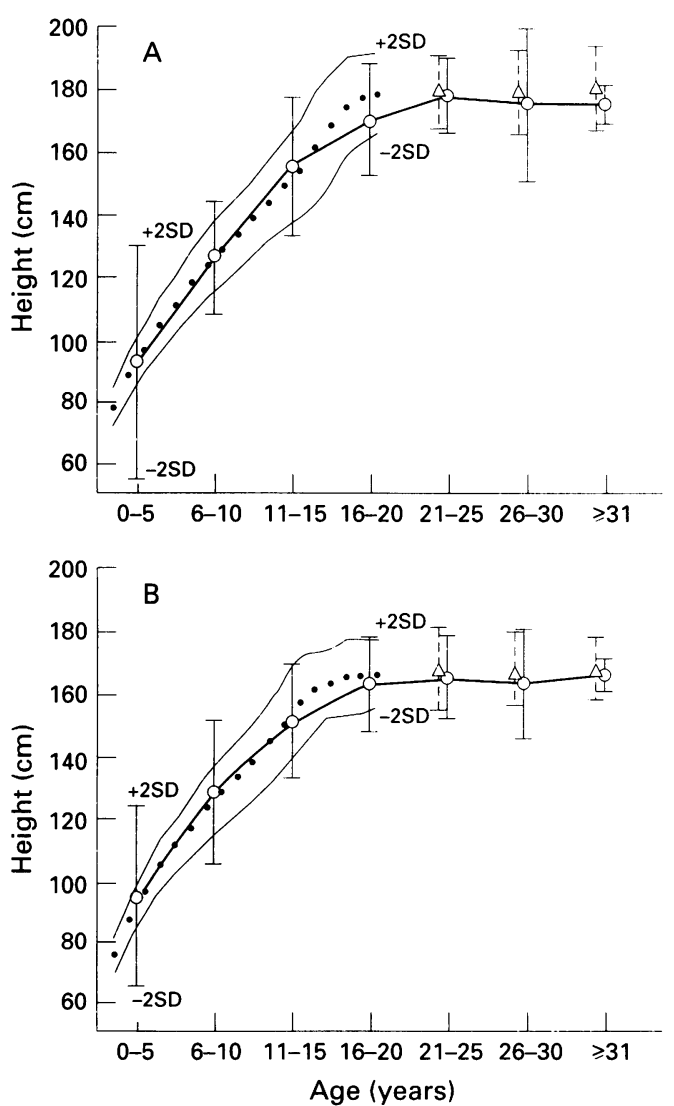

Figure 1 Height of (A) 115 Danish males and (B) 108 females with cystic fibrosis (median $(O \pm 2 S D)$ in five year age groups. The median height $(0) \pm 2 S D$ of normal Danish males and females until age 18 is shown for each year, and the median height (4) $\pm 2 S D$ of normal males and females aged between 20 and 40 years in five year age groups. The numbers of males with cystic fibrosis in each age group beginning with the youngest are: $17,20,21,24,17,9$, and 7 , and the numbers of females are $19,19,27,18,13,10$, and 2 . 

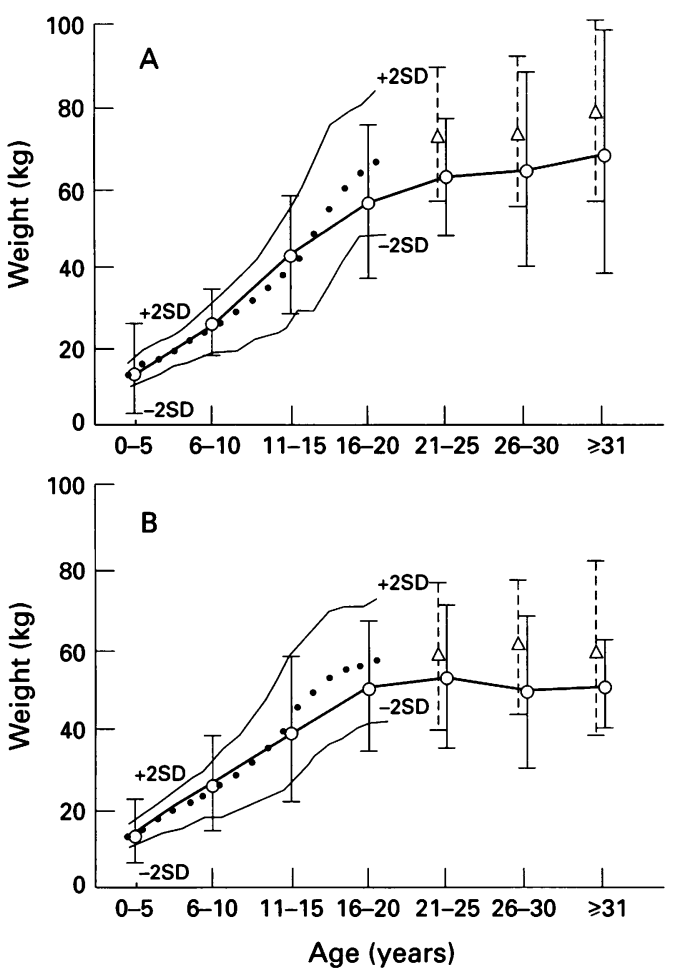

Figure 2 Weight of (A) 115 Danish males and (B) 108 females with cystic fibrosis (median (O) $\pm 2 S D$ ) in five year age groups compared with the median weight (O) $\pm 2 S D$ of normal Danish males and females. Symbols and numbers of patients in each age group as for fig 1 .

average whereas overall weight was $0.60 \mathrm{SD}$ below normal average in males and $0.70 \mathrm{SD}$ in females. The overall median BMI, which provided a good estimate of weight for height, was $96 \%$ of normal median BMI.

Figure 1 shows the actual heights of the patients with cystic fibrosis compared with the height of normal Danish males and females in relation to their age. The heights of both males and females with cystic fibrosis were similar to the normal Danish population. However, the number of females older than 30 years was too small for statistical comparison. The final heights of both men and women with cystic fibrosis are reached later than in controls, although this delay also did not reach statistical significance.

Figure 2 shows the weight of the patients in relation to age, together with the median weight of normal Danish males and females. Boys aged $0-5$ years with cystic fibrosis were heavier than their normal counterparts (mean body weight $13.3 \mathrm{~kg}$ versus $12.5 \mathrm{~kg}, \mathrm{p}<0.05$ ), but the body weight of boys with cystic fibrosis in the 6-10 and 11-15 year age groups did not differ significantly from those of normal boys of the same age (fig $2 \mathrm{~A}$ ). However, above the age of 15 years males with cystic fibrosis were significantly lighter than their normal counterparts ( $p<0.0005$ for the $16-25$ age group, $\mathrm{p}<0.05$ for those aged 26-30, and $\mathrm{p}<0.005$ for men above 30 years). The pattern for girls with cystic fibrosis (fig 2B) was the same as for the boys but the decline in weight began after the age of 10 . Girls with cystic fibrosis aged 0-5 years were heavier than normal Danish girls $(p<0.0005)$, but the weight in the $6-10$
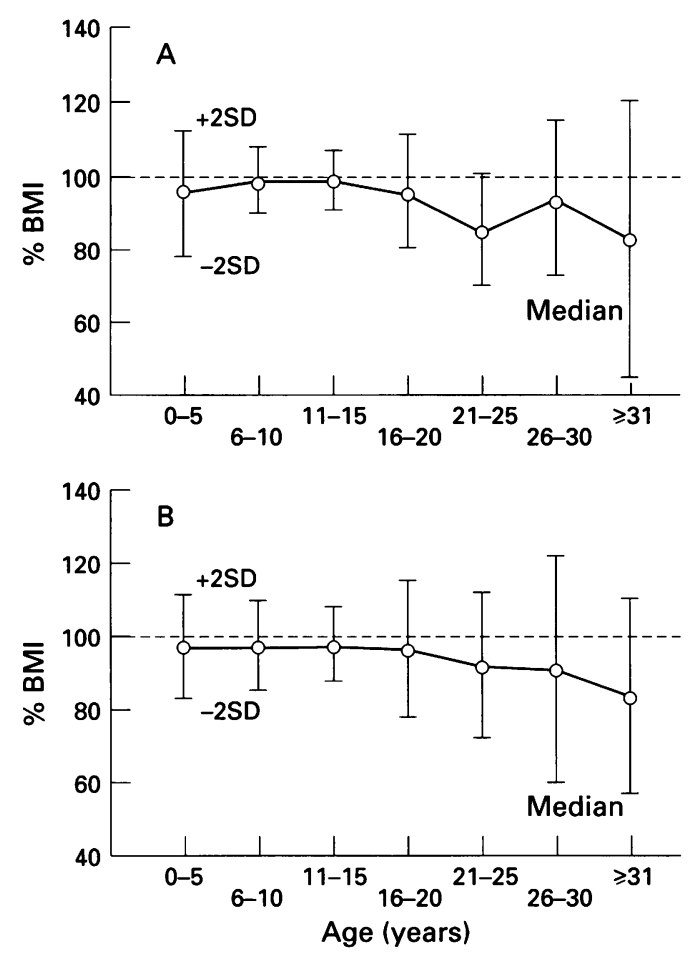

Figure 3 Body mass index (BMI) of (A) 115 Danish males and (B) 108 Danish females with cystic fibrosis as a percentage of the BMI of normal Danish males and females (median (O) $\pm 2 S D$ ). The numbers of patients in each group are as for fig 1 .

age group was the same as normal. Above 10 years girls and women with cystic fibrosis were lighter than normal $(p<0.001$ for the $11-20$ age group, $\mathrm{p}<0.005$ for those aged $21-25$ years, and $p<0.001$ for those in the $26-30$ age group).

The median $\mathrm{BMI}$ as a percentage of the $\mathrm{BMI}$ of the normal Danish population matched for age and sex is shown in fig 3. The BMI was close to normal until age 20 in patients with cystic fibrosis of both sexes whereafter it declined to about $90 \%$ of normal in men with cystic fibrosis and to approximately $80 \%$ in women. After the age of 30 years this decline was a result of increasingly lower weights in the adult patients who attained normal height.

As the figures only show median values of height and weight with the possibility of hiding the lightest and shortest of our patients, we looked specifically at those most growth retarded - that is, below the third percentile $(-1.88 \mathrm{SD})$ of the normal population. They comprised $10 \%$ of males and females for height, and $9 \%$ of males and $8 \%$ of females for weight. However, $28 \%$ of males and $30 \%$ of females were higher than the 50th percentile of the normal Danish population and $27 \%$ of males and $26 \%$ of females were heavier.

Table 1 shows correlations between the BMI and key parameters influencing the clinical status of our patients. BMI declined significantly with age for both male and female patients and with the duration of chronic $P$ aeruginosa infection in males. There was a strong positive correlation between the BMI and dynamic lung function parameters: $\mathrm{FEV}_{1} \%(\mathrm{R}=0.52$ in males and 0.55 in females, $p<0.0001$ ) and 
Table 1 Correlation between body mass index (BMI) and key clinical parameters in Danish patients with cystic fibrosis

\begin{tabular}{|c|c|c|c|c|}
\hline & \multicolumn{2}{|l|}{ Males } & \multicolumn{2}{|l|}{ Females } \\
\hline & $R$ & $p^{*}$ & $R$ & $p^{*}$ \\
\hline $\begin{array}{l}\text { Age } \\
\text { Duration of chronic } P \text { aeruginosa infection** } \\
\text { FEV }_{1} \% * * * \\
\text { FVC\%*** }\end{array}$ & $\begin{array}{r}-0.3491 \\
-0.2460 \\
0.5201 \\
0.4065\end{array}$ & $\begin{aligned} & 0.0005 \\
&< 0.01 \\
&<0.0001 \\
& 0.0001\end{aligned}$ & $\begin{array}{r}-0.2808 \\
-0.1765 \\
0.5450 \\
0.4867\end{array}$ & $\begin{array}{l}0.005 \\
\text { NS } \\
<0.0001 \\
<0.0001\end{array}$ \\
\hline
\end{tabular}

${ }^{*}$ Spearman rank correlation test.

** Chronic $P$ aeruginosa infection was present in 138 patients ( 74 males $(62 \%)$ ) with a mean duration of nine years (range 0.3-24). The age at onset of the infection was 15 months to 30 years (median 10 years).

***Determined in 173 patients $(89$ males $(51 \%)$ ) aged 7-41 years (median 18). Median (SD) forced vital capacity (FVC) was 85 (23)\% of predicted and forced expiratory volume in one second $\left(\mathrm{FEV}_{1}\right)$ was $65(24) \%$. FEV , but not FVC, was significantly lower in patients infected with $P$ aeruginosa than in those not infected $(60 \%$ versus $76 \%, \mathrm{p}<0.0005$, Mann-Whitney test). Neither FEV, nor FVC correlated with the duration of chronic $P$ aeruginosa infection.

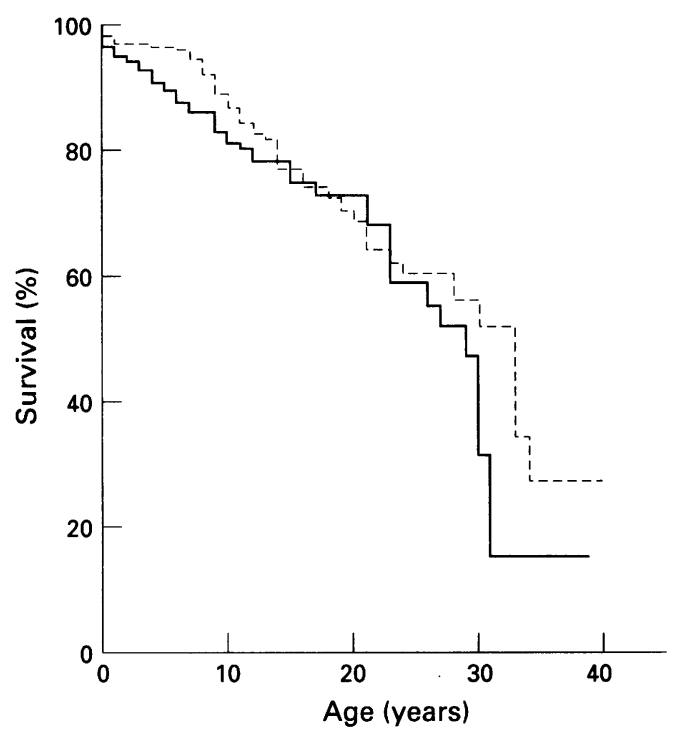

Figure 4 Survival of 163 male (----) and 150 female $(\longrightarrow)$ patients with cystic fibrosis born without meconium ileus in the period 1948-89.

FVC $\%(R=0.41, p=0.0001$ in males, $R=$ $0.49, \mathrm{p}<0.0001$ in females).

There was no correlation between BMI and pancreatic insufficiency as determined by the number of Pancrease capsules supplemented per $\mathrm{m}^{2}$ of body surface per meal (0-48 capsules, median 8.3) or per kg of body weight per meal (0-1.9 capsules, median 0.27 ). The BMI did not correlate with the DNA type expressed as homozygosity/heterozygosity for the $\Delta \mathrm{F} 508$ mutation in 218 of the patients ( 172 patients (79\%) were homozygous and $46(20 \%)$ heterozygous). The number of Pancrease capsules used correlated strongly with the DNA type ( $p$ $<0.0002$ for number of capsules per $\mathrm{m}^{2} /$ meal and $\mathrm{p}<0.0004$ per $\mathrm{kg} / \mathrm{meal}$, Mann-Whitney test).

In 1989 the median survival was 30 years for all patients born without meconium ileus. No sex differences in survival were detected, with the median survival being 29 years for females and 32 for males (fig 4). The median age of survival did not change if the 26 patients born with meconium ileus between 1949 and 1989 were included.

\section{Discussion}

This cross sectional study of growth and survival of Danish patients with cystic fibrosis who were receiving a normal unrestricted diet without hyperalimentation revealed normal height in all age groups and normal weight and BMI in prepubertal patients, but below normal weight in adolescents and adults. The percentage of growth retarded patients (below the third percentile) was similar to that published from Toronto ${ }^{12}$ and lower than that reported from Australia. ${ }^{20}$ Low weight and BMI were both clearly related to age (figs 2 and 3 ).

The median survival rates are similar to the best survival results published from other big cystic fibrosis centres ${ }^{121}$ and seven years more than that of patients treated in our centre between 1970 and $1981 .^{22}$ The shape of the overall survival curves (fig 4) clearly demonstrates an excess mortality in older patients.

Our treatment policy was fairly uniform until around 1975. In 1976 the treatment of chronic $P$ aeruginosa lung infection was changed from treating acute exacerbations only to regular intravenous chemotherapy four times per year with a subsequent significant decrease in mortality in $P$ aeruginosa infected patients. ${ }^{2324}$ Furthermore, a decrease in the incidence of chronic $P$ aeruginosa infection followed segregation of infected and non-infected patients after $1981^{25}$ and the introduction some years later of early treatment of $P$ aeruginosa colonisation. ${ }^{26}$ In 1985 the previously recommended low fat diet was abolished and a high calorie, high fat diet was recommended.

The data on weight, BMI, and survival in relation to age indicate that poor growth and excess mortality are predominantly features of older patients. Both could be related to inadequate anti-pseudomonas treatment before 1976 as well as to poor nutrition before 1985 . The immediate decrease in annual mortality after changing to a more aggressive antipseudomonas treatment regimen in 1976 suggests that the excess mortality in older patients, many already infected with $P$ aeruginos $a$ before 1976 , was related to inadequate anti-pseudomonas treatment. It is also probable that poor nutrition in older patients was the consequence of longstanding poorly controlled infection.

There is evidence that weight loss is caused by chronic lung infection. ${ }^{527}$ Decreased protein synthesis and increased resting energy expenditure (REE) during acute exacerbations of chronic pulmonary disease have been reported in patients with cystic fibrosis ${ }^{28}$ as well as a negative correlation between REE and pulmonary function. ${ }^{29}$ Infection with $P$ aeruginosa causes secretion of cytokines, including tumour necrosis factor alpha which acts as cachectin causing anorexia and weight loss. ${ }^{30}$ In children with asthma the REE was significantly higher than in controls, probably as a result of the inflammatory process and the additional energy used in the work of breathing. ${ }^{31}$ The strong correlation of BMI with dynamic lung function indices suggests that patients with poorer control of lower respiratory tract infections are those with the greatest loss of weight. 
Normal growth in our patients with cystic fibrosis was thus achieved by an unrestricted diet and individual guidance on the addition of pancreatic enzymes, without the use of tube feeding or parenteral nutrition. However, decreasing weight and BMI occurred in patients over 15 years of age.

The issue of whether poor nutritional status is predominantly caused by longstanding infection or whether inadequate calorie intake leads to more aggressive lung disease is not solved in this study, but should be addressed in a prospective controlled clinical study.

1 MacDonald A, Holden C, Harris G. Nutritional strategies in cystic fibrosis: current issues. F R Soc Med 1991;Suppl 18:28-35.

2 Bertrand JM, Morin CL, Lasalle R, Patrick J, Coates A Short-term clinical, nutritional, and functional effects of continuous elemental enteral alimentation in children with cystic fibrosis. $\mathcal{F}$ Pediatr 1984;104:41-6.

3 O'Loughlin E, Forbes D, Parsons H, Scott B, Cooper D, Gall G. Nutritional rehabilitation of malnourished patients with cystic fibrosis. Am $\mathcal{F}$ Clin Nutr 1986;43:732-7.

4 Shepherd RW, Holt TL, Thomas BJ, Kay L, Isles A, Francis PJ, Ward LC. Nutritional rehabilitation in cystic fibrosis: controlled studies of effects on nutritional growth retardation, body protein turnover, and course of pulmonary disease. F Pediatr 1986;109:788-94.

5 Shepherd RW, Holt TL, Cleghorn G, Ward LC, Isles A, Francis P. Short-term nutritional supplementation during management of pulmonary exacerbations in cystic fibrosis: a controlled study, including effects on protein turnover. Am 7 Clin Nutr 1988;48:235-9.

6 Levy DL, Durie PR, Pencharz PB, Corey ML. Effects of long-term nutritional rehabilitation on body composition and clinical status in malnourished children and adolescents with cystic fibrosis. F Pediatr 1985;107:225-30.

7 Gaskin KJ, Waters DL, Baur LA, Soutter VL, Gruca MA. Nutritional status, growth and development in children undergoing intensive treatment for cystic fibrosis. Acta Paediatr Scand (Suppl) 1990;366:106-10.

8 Vaisman N, Clarke R, Pencharz PB. Nutritional rehabilitation increases resting energy expenditure without affecting protein turnover in patients with cystic fibrosis. affecting protein turnover in patients with cysti
P Pediatr Gastmenterol Nutr 1991;13:383-90.

9 Boland MP, Stoski DS, MacDonald NE, Soucy P, Patrick J. Chronic jejunostomy feeding with a non-elemental forJ. Chronic jejunostomy feeding with a non-elemental for-
mula in undernourished patients with cystic fibrosis. mula in undernouris

10 Shepherd RW, Cooksley WGE, Cooke WDD. Improved growth and clinical, nutritional, and respiratory changes in response to nutritional therapy in cystic fibrosis. $\mathcal{f}$ Pediatr 1980;97:351-7.

11 Mansell AI, Andersen JC, Muttart CR, Ores CN, Loeff DS, Levy JS, et al. Short-term pulmonary effects of total parenteral nutrition in children with cystic fibrosis. $\mathcal{F}$ Pediatr 1984;104:700-5.
12 Corey M, McLaughlin FJ, Williams M, Levison H. A comparison of survival, growth, and pulmonary function in patients with cystic fibrosis in Boston and Toronto. $\mathrm{F} \mathrm{Clin}$ Epidemiol 1988;6:583-91.

13 Koch C, Høiby N. Management of cystic fibrosis in Copenhagen. Thorax 1991;46:385-6.

14 Pedersen SS, Jensen T, Høiby N, Koch C, Flensborg EW. Management of Pseudomonas aeruginosa lung infection in Danish cystic fibrosis patients. Acta Paediatr Scand 1987 76:955-61.

15 Andersen E, Hutchings B. Jansen J, Nyholm M. Heights and weights of Danish children. Ugeskr Laeger 1982;144: $1760-5$.

16 The Copenhagen City Heart Study Group. The Copenhagen City Heart Study. Osterbroundersogelsen. Scand f Social Med 1991;Suppl 41:88-93.

17 Ibsen KK. Factors influencing blood pressure in children and adolescents. Acta Paediatr Scand 1985;74:416-22.

18 Polgar GE, Promadhad V. Pulmonary function testing in children: techniques and standards. Philadelphia: WB Saunchildren: techniques and standards.
ders, 1971: 88-107, 178-80.

19 Schwartz M, Johansen HK, Koch C, et al. Frequency of the delta F508 mutation on cystic fibrosis chromosomes in Denmark. Hum Genet 1990;85:427-8.

20 Soutter VL, Kristidis P, Gruca MA, Gaskin KJ. Chronic undernutrition/growth retardation in cystic fibrosis. Clin Gastroenterol 1986;15:137-55.

21 FitzSimmonns SC. The changing epidemiology of cystic fibrosis. F Pediatr 1993;122:1-9.

22 Nielsen OH, Schiøtz PO. Cystic fibrosis in Denmark in the period 1945-1981. Evaluation of centralized treatment. Acta Paediatr Scand 1982;Suppl 301:107-19.

23 Szaff M, Høiby N, Flensborg EW. Frequent antibiotic therapy improves survival of cystic fibrosis patients with chronic Pseudomonas aeruginosa infection. Acta Paediatr Scand 1983;72:651-7.

24 Pedersen SS, Jensen T, Høiby N, Koch C, Flensborg EW. Management of Pseudomonas aeruginosa lung infection in Danish cystic fibrosis patients. Acta Paediatr Scand 1987; 76:955-61.

25 Høiby N, Pedersen SS. Estimated risk of cross-infection with Pseudomonas aeruginosa in Danish cystic fibrosis patients. Acta Paediatr Scand 1989;78:395-404.

26 Valerius NH, Koch C, Høiby N. Prevention of chronic Pseudomonas aeruginosa colonization in cystic fibrosis by early treatment. Lancet 1991;338:725-6.

27 Kane RE, Hobbs P. Energy and respiratory metabolism in cystic fibrosis: the influence of carbohydrate content of nutritional supplements. $\mathcal{F}$ Pediatr Gastroenterol Nutr 1991; 12:217-23.

28 Holt TL, Thomas BJ, Ward LC, Shepherd RW. Nitrogen losses from sputum in cystic fibrosis: an unexpected factor losses from sputum in cystic fibrosis: an unexpected factor in assessing.

29 Vaisman N, Pencharz PB, Corey M, Canny GJ, Hahn E. Energy expenditure of patients with cystic fibrosis. $\mathcal{F}$ Pediatr 1987;111:496-500.

30 Suter S, Schaad UB, Roux-Lombard P, Girardin E, Grau G, Dayer J-M. Relation between tumor necrosis factoralpha and granulocyte elastase-alpha 1-proteinase inhibitor complexes in the plasma of patients with cystic fibrosis. Am Rev Respir Dis 1989;140:1640-4

31 Zeitlin SR, Bond S, Wootton S, Gregson RK, Radford M. Increased resting energy expenditure in childhood asthma: does this contribute towards growth failure? Arch Dis Child 1992;67:1366-9. 